\title{
Therapeutic Route of Patients with Cirrhosis in Bangui
}

\author{
Serges Magloire Camengo Police ${ }^{1 *}$, Peggy Guérendo², Georges Service3, Benoît Elowa1, \\ Gaétan Adouaka1, Eveline Mofini', Armelo Thibaut Yangba Kalebanga1, \\ Nathalie Philomène Boua-Akelelo1, Bernard Bessanguem¹, Joseph Roger Molowa Kobendo1
}

\author{
${ }^{1}$ Department of Hepato-Gastroenterology and Internal Medicine of “Amitié Sino-Centrafraine” University Hospital Center, \\ Bangui, Central African Republic \\ ${ }^{2}$ Department Venerology Dermatology, National University Hospital Center, Bangui, Central African Republic \\ ${ }^{3}$ Department of Internal Medicine “Maman Elisabeth Domitien” University Hospital Center, Bimbo, \\ Central African Republic \\ Email: *camengop@netcourrier.com
}

How to cite this paper: Police, S.M.C., Guérendo, P., Service, G., Elowa, B., Adouaka, G., Mofini, E., Kalebanga, A.T.Y., BouaAkeleo, N.P., Bessanguem, B. and Kobendo, J.R.M. (2020) Therapeutic Route of Patients with Cirrhosis in Bangui. Open Journal of Gastroenterology, 10, 88-96.

https://doi.org/10.4236/ojgas.2020.104009

Received: March 4, 2020

Accepted: April 17, 2020

Published: April 20, 2020

Copyright (C) 2020 by author(s) and Scientific Research Publishing Inc. This work is licensed under the Creative Commons Attribution International License (CC BY 4.0).

http://creativecommons.org/licenses/by/4.0/ 
Cirrhosis is diagnosed at the complication stage due to inappropriate treatment by pastors, marabouts and the general practitioner. The population must be made aware of the early use of health care facilities.

\section{Keywords}

Therapeutic Route, Cirrhosis, Bangui

\section{Introduction}

Cirrhosis is a public health problem due to its frequency and severity. It is one of the leading causes of death from liver disease. In France, the prevalence of cirrhosis is estimated at 2000 to 3300 cases per million inhabitants, with an annual incidence of 150 to 200 cases per million inhabitants [1]. In the USA, the prevalence in the general population is $0.27 \%$ [2]. In Africa, hospital prevalence is variable. It was 7.06\% in Lomé in Togo [3], 5.9\% in Ouagadougou in Burkina Faso [4]. In Bangui, in our department, cirrhosis represents $19.7 \%$ of hospitalizations and in $19.1 \%$ of cases, the diagnosis of cirrhosis is established at the decompensation stage [5]. This study has focused on understanding why cirrhosis is diagnosed late in our department. For this, we have set ourselves the goal of determining the therapeutic route of patients with cirrhosis admitted for the first time in our department.

\section{Patients and Methods}

We carried out in the department of hepato-gastroenterology and internal medicine of Bangui "Amitié Sino-Centrafricaine" University, Hospital Center, a cross-sectional study of a duration of 12 months going from October 1, 2013 to September 30, 2014. During this study, we included, consenting patients of both gender hospitalized for the first time for cirrhosis whatever the etiology. The diagnosis of cirrhosis was established on the existence of clinical and biological signs of hepatocellular insufficiency, clinical, ultrasound and endoscopic signs of portal hypertension and the characteristics of the liver (firm or hard, regular, painless liver, thin lower edges or sharp in case of hypertrophic liver). Liver biopsy puncture for pathology analysis and/or non-invasive fibrosis tests has not been performed. Patients already followed in the department for cirrhosis and those admitted for the first time for cirrhosis, but not consenting was not included. Data collection was done using an individual direct administration survey form. The variables studied were the socio-demographic characteristics (age, sex, marital status, religion), the knowledge of patients and those around them on cirrhosis, the course of care, the motivations for care, types of care, development under the former care, the cost of care. Our sample was for convenience of all cases meeting the inclusion criteria. The data was captured and analyzed using Epi Info 2008 software. It obtained frequencies, averages and standard devia- 
tion. In case of comparison, the Chi2 test will be used with a significance threshold $\mathrm{p}<0.05$.

\section{Results}

During the study period, 1028 patients were hospitalized in the department, including 202 (19.6\%) for cirrhosis. Among the patients with cirrhosis, we included 104 patients (10.1\%). Cirrhosis was due to the hepatitis B virus in 74 cases (71.2\%) including 11 cases associated with alcohol, the hepatitis $C$ virus in 12 cases (11.5\%), alcohol in 18 cases (17.3\%). Among the 104 patients with cirrhosis, there were 70 men $(67.3 \%)$ and 34 women (32.7\%). The sex ratio was 2.05 . The average age of the patients was $43.07 \pm 13.82$ years. Patients with cirrhosis and their parents did not know about cirrhosis, but claimed in 87 cases (83.6\%) that patients with signs of cirrhosis eventually died. Figure 1 shows the distribution by age group.

The religion of cirrhosis patients is shown in Figure 2.

The main clinical signs were abdominal bloating and lower extremity edema in 75 cases $(72.1 \%)$, jaundice in 18 cases $(17.3 \%)$, hematemesis in 11 cases $(10.6 \%)$. The presence of these signs had led patients to believe in a supernatural origin in 68 cases $(65.4 \%)$ and a natural origin in 36 cases (43.6\%). The supernatural origin was witchcraft in 42 cases (40.4\%) and the spell in 26 cases (25\%).

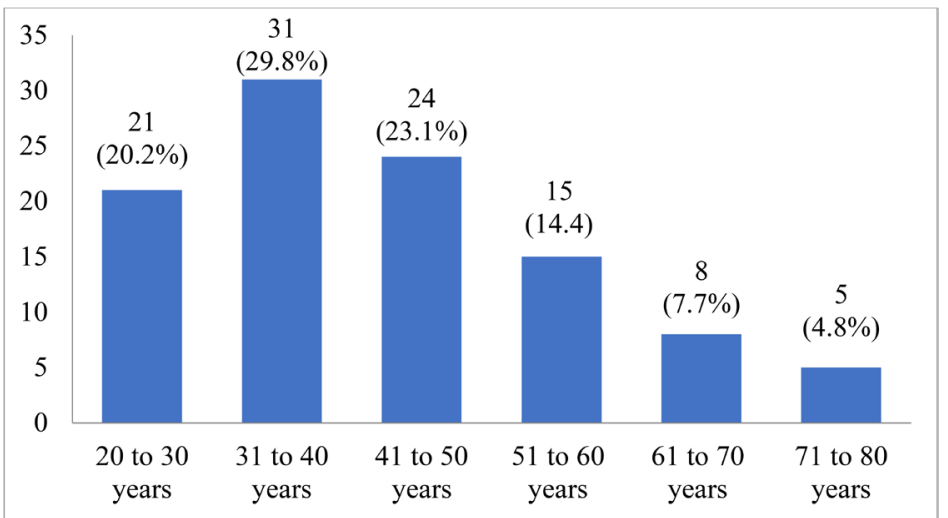

Figure 1. Breakdown by tranche of patients with cirrhosis.

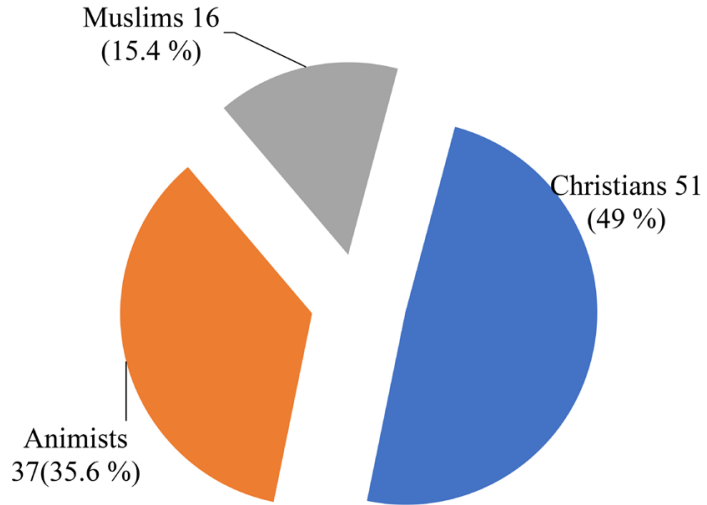

Figure 2. Distribution of patients by religion. 
As soon as signs of cirrhosis appear, 88 patients (84.6\%) should be seen. While 16 patients $(15.4 \%)$ did not immediately consult due to lack of financial resources in 12 cases (11.5\%) and lack of guidance in 4 cases (3.9\%). Among the 88 patients who had consulted before arriving at the hospital, 51 (59.8\%) were at stage C of Child-Pugh and $37(40.2 \%)$ at stage B. On the other hand, the 16 patients (15.4\%) who had not done any consultation before arriving at the hospital were all at Child-Pugh stage C. Table 1 shows the Child-Pugh stages according to the people consulted by the patients.

During the consultation, the pastor, the traditional healer and the marabout stated that the cirrhosis was serious and that healing could only be obtained through prayer respectively; taking traditional plants, scarifying and washing and ingesting black ink from the Quran. Prayer was the only treatment received by the 25 patients who had consulted the pastor. The traditional healer had administered oral herbal teas to patients in 18 cases, by rectal enema in 28 cases and by scarifications in 4 cases. The marabout wrote the prayer on the quanaric table which the patient repeated seven times during the day. Then the prayer on the board is washed and given to each patient to drink. The 75 patients $(72.1 \%)$ who had not seen the doctor at the first sign, were taking their medication for self-medication with street drugs. These were nonsteroidal anti-inflammatory drugs (NSAIDs) in 52 cases (69.3\%) sometimes associated with diuretics in 37 cases. Fifteen of 75 patients (20\%) were only taking diuretics. The course of the disease in patients treated with the traditional healer was stationary in 9 cases and marked by the appearance of complications in 25 cases. Complications were in order of frequency hepatic encephalopathy in 13 cases (53.3\%), digestive hemorrhage in 9 cases (36.7\%), abdominal pain in 3 cases (10\%). Among the 16 patients treated with marabout, $2(12.5 \%)$ had a stationary course and 14 (87.5\%) had presented complications which were hepatic encephalopathy in 7 cases (50\%), digestive hemorrhage in 5 cases (35.7\%), jaundice in 2 cases (14.3\%). The 25 patients treated by the pastor's prayer had a stationary state in 4 cases, while 21 had presented complications including hepatic encephalopathy in 10 cases (47.6\%), digestive hemorrhage in 6 cases (28.6\%), worsening ascites in 5 cases $(23.8 \%)$. Among the 25 patients who were taking non-steroidal anti-inflammatory drugs at the same time, 22 patients $(88 \%)$ had experienced digestive hemorrhage. The failure of different treatments and/or the occurrence of

Table 1. Distribution of patients by people consulted.

\begin{tabular}{cccc}
\hline Consultants & Stage Child-Pugh B (\%) & Stage Child-Pugh C (\%) & Effective (\%) \\
\hline Healer & $10(11.4)$ & $24(27.3)$ & $34(38.7)$ \\
Pastor & $8(9.1)$ & $17(19.3)$ & $25(28.4)$ \\
Marabout & $14(15.9)$ & $2(2.3)$ & $16(18.2)$ \\
General practitioner & $5(5.6)$ & $8(9.1)$ & $13(14.7)$ \\
Total & $37(42)$ & $51(58)$ & $88(100)$ \\
\hline
\end{tabular}


complications led patients to consult within an average of $74 \pm 15.3$ days. Hospital consultations were motivated by the lack of improvement in 55 cases (52.9\%), the parents' decision in 41 cases (39.4\%) and the healer's advice in 8 cases (7.7\%). After hospital care, 47 patients (45.2\%) believed that they had noticed a marked improvement in their condition. In contrast, 57 patients (54.8\%) had seen no improvement. The average length of hospital stay was $21.5 \pm 13$ days. The average cost of hospital care was 149,175 CFA francs (227.41€). The average cost of care at the pastor or marabout was 106,575 FCA (162.47€) not including payments in kind (kid, chicken, valuables such as mobile phones, costumes, luxury watches, jewelry in gold...).

\section{Discussion}

However, our study has some limitations. Patients arriving at an advanced stage of the disease would certainly not have given all the information about their care pathway. We did not perform the liver biopsy puncture for histological analysis, which in our context should only be done, by the transcutaneous route. The presence of ascites in our patients was a contraindication to liver biopsy puncture. The presence of clinical and biological signs of hepatocellular insufficiency, clinical, ultrasound and endoscopic signs of portal hypertension and in the case of a large firm or hard, regular, painless liver with a thin or sharp lower edge or a liver of normal size of an altered echostructure or an atrophic liver on ultrasound, it was easy for us to remember the diagnosis of cirrhosis. The French High Authority for Health recommends that in the event of concurring epidemiological, clinical and morphological arguments, the diagnosis of cirrhosis can be accepted without resorting to liver biopsy puncture [1]. It was also difficult for us to accurately assess the cost of care. However, this study, the first in Bangui, allowed us to contribute to improving the management of cirrhosis by understanding why our patients reach a complicating stage.

The hospital frequency of cirrhosis of $19.6 \%$ in our study is similar to that already reported in the department, which was $19.7 \%$ [4]. Our frequency is lower than that observed in Cotonou which is $22.6 \%$ [6]. Cirrhosis is the most common liver disease in hospitals in sub-Saharan Africa. The primary cause of cirrhosis in our study is the virus in hepatitis B (71.2\%). The authors in Lomé in Togo [3], in Ouagadougou in Burkina Faso [4], in Cotonou in Benin [6], in Pointe Noire in Congo Brazzaville [7] and in Kindia in Guinea [8] also reported that HBV is the number one cause of cirrhosis. While in France [1] and the USA [2], cirrhosis is caused by HCV and alcohol. The etiological difference of cirrhosis between the West and Sub-Saharan Africa is explained by the fact that Sub-Saharan Africa is in the zone of high endemicity for HBV. Men had twice as much cirrhosis as women in our series. The predominance of men in our study corroborates the data in the literature [3] [4] [6] [7] [8] [9]. The average age of our patients was $43.07 \pm 13.82$ years. It is similar to that reported by the authors in Bamako which is $43.7 \pm 15.3$ years [10], but lower than that of patients in 
Lomé [3] and in Cotonou [6] who is 49 years and in Tunis 58 years old [11]. In France, the average age at the time of diagnosis of cirrhosis is 55 years [1]. Patients aged 40 or less made up half the sample in our series. These results show that cirrhosis is more common in young adults in sub-Saharan Africa. The patients were Christians in $49 \%$ of the cases, animists in $35.6 \%$ of the cases and Muslims in 15.4 of the cases. The high proportion of Christians in our work would probably be linked to the fact that, the Central African Republic is a country with a Christian majority and that the patients orient themselves according to their religious affiliation. The most frequent clinical signs presented by the patients were abdominal bloating reflecting ascites in 75 cases (72.1\%), jaundice in 18 cases (17.3\%), hematemesis in 11 cases (10.6\%). Ascites and jaundice were the main symptoms reported by the authors in Lomé in Togo [3], in Ouagadougou in Burkina Faso [4], in Cotonou in Benin [6] and in Bamako in Mali [9]. These signs led patients to believe in a supernatural origin (65.4\%) due to witchcraft $(40.4 \%)$ and bewitchment (25\%). These beliefs had led patients to resort to non-medical care (pastor, traditional healer, marabout), thus delaying treatment in a hospital environment. The various treatments received by patients before arrival at the hospital were responsible for complications, notably hepatic encephalopathy and digestive hemorrhage. Hepatic encephalopathy was the formidable complication observed in $74.6 \%$ among cirrhotics in Bamako [12]. It was observed in $31.2 \%$ in Lomé in Togo [3]. It could certainly in our series related to digestive hemorrhage, delay in consultation and traditional treatment. In our study like those of other authors [6], the majority of patients arrived at stage $B$ and $C$ of Child-Pugh. It reflects the advanced stage at which the diagnosis is made in our communities. The average duration of out-of-hospital care was 74 days \pm 15.3 . While the average length of hospital stay was $21.5 \pm 13$ days. In Lomé, $78.1 \%$ of patients consulted one year after the development of cirrhosis [3]. These patients would certainly seek other care before arriving at the hospital. The population should be made aware of the early use of health care facilities in order to minimize the cost of care. Patients arrive at the hospital after spending too much on healers, marabouts or pastors. This could explain the fact that patients were no longer able to manage themselves in hospital. The average cost of hospital care was 149,175 CFA francs (227.41€). This cost is lower than that already estimated in the service, which was 194,170 f CFA (236€) [13]. In Brazzaville, the hospital cost of hospital treatment for uncomplicated cirrhosis is 205,615 CFA francs (313.9€) and varies depending on the mode of decompensation [14]. The difference is explained by the financial difficulty experienced by patients to perform certain additional examinations.

\section{Conclusion}

The late diagnosis of cirrhosis in our context is linked to prejudices, in particular witchcraft and bewitchment, which push patients first to non-medical care, sources of complications leading them later to consultation in hospital. It is im- 
portant to raise awareness among the population about the early use of health care structures in the event of illness and also to set up a system of health cover making it possible to facilitate access to quality care for the population.

\section{Conflicts of Interest}

The authors declare no conflicts of interest regarding the publication of this paper.

\section{References}

[1] Haute Autorité de Santé (2008) Guide affection longue durée: cirrhoses 2008. http://www.conf-plus.com/1011/fichiers/CS_GASTRO_10_d1.pdf

[2] Scaglione, S., Kliethermes, S., Cao, G., et al. (2015) The Epidemiology of Cirrhosis in the United States: A Population-Based Study. Journal of Clinical Gastroenterology, 49, 690-696. https://doi.org/10.1097/MCG.0000000000000208

[3] Bouglouga, O., Bany, A., Djibril, M.A., et al. (2012) Aspects épidémiologiques, diagnostiques et évolutifs de la cirrhose hépatique dans le service d'hépato-gastroentérologie du CHU Campus de Lomé. Journal de Recherches Scientifiques de I Université de Lomé( Togo), Série D, 14, 1-7.

[4] Serme, A.K., Ilboudo, P.D., Bougouma, A., et al. (2002) Cirrhosis in a National Teaching Hospital Yalgado Ouedraogo (CNHYO): Epidemiological and Clinical Aspects. Médecine d Afrique Noire, 49, 481-486.

[5] Camengo Police, S.M., Koffi, B., Boua-Akelelo, N.P., et al. (2014) Complications of the Cirrhosis to the University Hospital "Amitié" of Bangui. Médecine d Afrique Noire, 61, 537-542.

[6] Sehonou, J., Kodjoh, N., Sake, K., et al. (2010) Liver Cirrhosis in Cotonou, Republic of Benin: Clinical Aspects and Factors Related to Death. Médecine Tropicale, 70, 375-378.

[7] Bossali, F., Koumou Okandze, L., Katende, S., et al. (2011) Seroprevalence of Hepatitis B in Patients with Cirrhosis and Patients with Hepatocellular Carcinoma in Pointe-Noire 2005-2008. Journal Africain d Hépatologie Gastroentérologie, 5, 2-5. https://doi.org/10.1007/s12157-010-0224-4

[8] Diallo, A.A.S., Meliho, C., Sylla, A.I., et al. (2018) Cirrhosis of the Liver: Epidemiological, Diagnostic and Progressive Characteristics in the Service of General Medicine at Kindia Regional Hospital (Guinea). Journal of African Clinical cases and Reviews Africa, 2, 240-250.

[9] Diarra, M., Maïga, M.Y. and Konaté, A. (2010) Aspects évolutifs des malades cirrhotiques dans un service d'Hépato-gastroentérologie au Mali. Mali Médical, XXV, 42-46.

[10] Maïga, M.Y., Dembele, M., Traoré, H.A., et al. (2002) Upper Digestive Endoscopy in the Diagnosis of Cirrhosis. Acta Endoscopica, 32, 211-218.

http://hdl.handle.net/2042/7506 https://doi.org/10.1007/BF03016657

[11] Ennaifer, R., Cheikh, M., Romdhane, H., et al. (2016) L'hyponatrémie au cours de la cirrhose: Facteurs de risque et valeur pronostique. La Tunisie Médicale, 94, 401-405.

[12] Katilé, D., Dicko, M.Y., Doumbia Samake, K., et al. (2017) Hepatic Encephalopathy in Cirrhosis in Bamako. Journal Africain d Hépatologie Gastroentérologie, 11, 78-80. https://doi.org/10.1007/s12157-017-0709-5 
[13] Camengo Police, S.M., Mbeko Simaleko, M., Boua-Akelelo, N.P., et al. (2013) The Cirrhosis and Her Complications to the Academic Hospital of the Friendship of Bangui: Survey of the Financial Cost of the Old in Charge. Journal Africain d Hépatologie Gastroentérologie, 7, 78-81. https://doi.org/10.1007/s12157-013-0454-3

[14] Atipo-Ibara, B.I., Ondele-Ngoli, A., Deby-Gassaye, et al. (2004) Cost of Managing Cirrhosis and Related Complications at the University Hospital in Brazzaville, Congo. Médecine Tropicale, 64, 50-52. 


\section{Investigation Sheet on Therapeutic Route of Patients with Cirrhosis in Bangui}

Identification number /__ /_____ I

Codification

1. Sex: 1 male / / 0 Female / /

I_II_

2. Age: /___/ years

3. Religion: 1 Christian /_/ 2 Muslim /_/ 3 Animist /_/ 4 others:

1.1

2. I_l

3. I_I

4. /_/

Do you know cirrhosis? 1 yes / / 0 no / /

5. Do you know someone who suffered from cirrhosis? 1 yes /__ 2 no /__

5. /_l

6. If yes, for you is this disease: 1 not serious /__/ 2 serious /__/ 3 pas de réponse /__

6. I_I

7. I_I

7. What do you think of the origin of cirrhosis: 1 . Natural /__/ 2 supernatural /__/

8. If the origine is supernatural, do you think it is: 1 wichcraft /__/ 2 spell /__ 3 no answer /__ 4 others:

8. I_l

9. What do you think of his prognosis? 1 evolution towards healing /__/ 2 evolution to death /_/ 3 no answer /__/

9. / I

10. What signs you have presented?

10.1. Abdominal bloating: 1 yes /__ / 0 no /__/

10.2. Abdominal pain: 1 yes /__ / 0 no /__ /

10.3. Edea of lower limbs: 1 yes /__ 0 no /__

10

10.4. jaundice: 1 yes /__/ 0 no /__/

10.5. digestive hemorrhage: 1 yes /__ 0 no /__ I

10.2. /_/

10.3. /_/

10.4. /_/

10.5. I_/

11. Have you viewed from the appearance of the first signs? 1 yes /__ 0 no /__

11. /_I

11.1. If yes, who have you consulted? 1 General practitioner /__ 2 Marabout /__/ 4 Pastor ou Priest /__/ 8 Healer /__/

11.2. If no, give the reason for the no-consultation: 1 lack of financial means/__ 2 no one to go to me /__/ 4 the fear of the disease /__ 8 11.2. I_/ others, specify

12. What was the opinion of the one who consulted to me the first on the cirrhosis? 1 serious illness /__/ 2 curable disease /__/ 3 others, specify

13. What are the therapeutic means that have been proposed to you? 1 Pray /__/ 2 inguestion of traditional plants /__/ 4 medicine medications /__ 8 inguestion of the quanaric inck ink /__/ 16 others, specify

13.1. If you have consumed traditional plants, what was the route of administration? 1 oral herbal tea /__ 2 rectal enema /__/ 4 scarification /__/

14. Have you also self-medicated? 1 yes /__ 0 no /__ /

14.1. If yes, drugs were purchased: 1 at the pharmacy /__ 0 on the street/__

14.2. If yes, what medication did you take? 1 analgesic /__/ 2 non steroidal anti inflammatory drugs /__/ 4 diuretic /__/ 8 antibiotic/_/ 16 others, specify

15. What was the evolution of the disease under the different treatments used? 1 stationary /__/ 2 regression of signs /__/ 3 onset of complications /_/

15.1. If complications appear, specify which ones:

15.1.1. Abdominal pain: 1 yes /__ 0 no /__

15.1.2. Digestive hemorrhage: 1 yes /__/ 0 no /__ /

15.1.3. consciouness: 1 yes /__ / 0 no /__ /

15.1.4. Jaundice: 1 yes /__ / 0 no /__/

15.1.5. Ascites increased: 1 yes /__ 0 no /__ /

16. How long after the various treatments and / or failed treatment did you come to the hospital?/_______ days

17. How did you pay the consultation fees: 1 cash /__/ 2 in kind /__/

17.1. If in kind, specify

17.2. Can you estimate the amount of what you spent during this treatment (transport, consultation costs, cost of medication, etc.):

I_I_I_I_/_fcfa equivalent in Euro /_I_I_/_/ €

18. Why did you come to the hospital? 1 lack of improvement /__/ 2 by parents' decision /__/4 on advice from the healer/__/ 8 others, specify

19. What is the etiology of cirrhosis: 1 alcohol /__/ 2 hepatitis virus B /__/ 4 hepatitis virus C /__ 8 hepatitis virus Delta.

20. What is the Child-Pugh score? 1 class A /__ 2 class B /__ 3 class C /_/

21. How do you estimate the evolution in hospital? 1 stationary /_/ 2 a good evolution/__/ 3 an aggravation /__

22. What is the time of hospitalization? /______/ days

23. How much you could you estimate the cost of hospital care? (transport, consultation costs, hospitalization fees, fresh biodiversity and mophological examination, drug fees): /_/_/_/_/_/fcfa ou Euro /_/_/_/_/_/ 